Journal of Advanced Research in Fluid Mechanics and Thermal Sciences

Journal homepage: www.akademiabaru.com/arfmts.html ISSN: 2289-7879

\title{
Experimental Study the Effect of Turbine Distance on Cross Flow Wind Turbine Performance in In-Line Configuration with Counter-Rotating Wind Turbine
}

\author{
Sarah Islamiati Pertiwi ${ }^{1}$, Dominicus Danardono Dwi Prija Tjahjana ${ }^{1,}{ }^{*}$, Sukmaji Indro Cahyono ${ }^{1}$ \\ Mechanical Engineering Department, Universitas Sebelas Maret, Surakarta, Jawa Tengah, Indonesia
}

\section{ARTICLE INFO \\ ABSTRACT}

\section{Article history:}

Received 25 January 2020

Received in revised form 30 March 2020

Accepted 3 April 2020

Available online 30 April 2020

Keywords:

Cross Flow Wind Turbine; Wind Energy;

In-line Configuration
Indonesia potentially has a wind energy sources that is 950 Megawatt. However, development of wind energy that has been implemented only reached 1.3 Megawatt or $0.13 \%$. One of the studies that is being developed is using cross flow runner since it suitable with the condition in Indonesia, which has low wind speed and can catch wind from all direction. This study focuses on experiment using in-line configuration and expected to minimize reduce of torsion and to know the effect of power characteristic. Considered changes are made on distance between two turbines that is $1.5 \mathrm{D} ; 2 \mathrm{D} ; 2.5 \mathrm{D}$ in varied $5 \mathrm{~m} / \mathrm{s} ; 6 \mathrm{~m} / \mathrm{s} ; 7 \mathrm{~m} / \mathrm{s}$ of wind speed. The research was carried out by using cross flow wind turbine with $200 \mathrm{~mm}$ in diameter and $200 \mathrm{~mm}$ in height in the wind tunnel. Based on this study, it can be concluded that the distance of turbine in in-line configuration with counter-rotating cross flow wind turbine affects the torsion and power coefficient.

\section{Introduction}

The main energy source in the world, especially Indonesia, is from fossil energy where its availability is running low. Fossil energy is classified as non-renewable sources, where it has limited availability. In 2015 the use of fossil energy, to keep the needs of both primary and secondary of society, reached 90 percent [1]. It is undeniable that the needs for energy increases with time. Based on studies conducted by the government, energy demand in Indonesia will double by 2025 compared to 2000, even for electricity energy could increase four times [2]. To conquer this limitedness of energy that occur, various studies have been carried out to obtain alternative energy sources whose availability can keep existing energy needs.

Alternative energy has set up to be used in several countries as a substitute for fossil energy, where alternative energy is classified as renewable energy. In Indonesia distinctively, the use of

\footnotetext{
* Corresponding author.

E-mail address: danar1405@gmail.com (Dominicus Danardono Dwi Prija Tjahjana)
} 
renewable energy (alternative) has begun to be used, but it has not been maximized. Indonesia has renewable energy potential including wind energy of 950 Megawatts, solar power of 11 Gigawatts, water power of 75 Gigawatts, etc. Wind energy which is one of the potentials of renewable energy is one of the energies that is being intensively utilized, where this energy is clean energy and the process of its production does not pollute the environment [3].

There are several factors should be considered to optimize the aerodynamic performance of wind turbines, for example the design of a wind turbine, the choice of the location of the turbine application, and the layout of the wind turbine [4].

One of the experiments conducted was the performance of a cross flow VAWT wind turbine by Dragomirescu in 2011 with a simulation method using ANSYS-Fluent software. Based on the test results, it was found that the cross-flow turbine can work at a low tip speed ratio. In addition, the crossflow turbine also has a simple design that is easy for the manufacturing process [5].

Ahmadi conducted research on aerodynamic interactions on five Straight-Blade VAWT configurations made by Shanghai Aeolus Wind Power Technology Co., Ltd. The study was conducted with a wind tunnel by regulating two wind turbines in counter / co-rotating (1D) direction and three wind turbines with various downstream directions $(1.5 ; 3 ; 4,5) \mathrm{D}$ and turbine separation distance to the side $(0.5 ; 1 ; 1.5) \mathrm{D}$. Wind speeds are varied between $6-14 \mathrm{~m} / \mathrm{s}$ with an increase every $2 \mathrm{~m} / \mathrm{s}$. The results obtained are testing by counter-rotating two wind turbines increasing a slight increase in aerodynamic performance compared to one turbine. The results also showed that the most generated resource at the turbine distance to the back of $3 \mathrm{D}$, while the distance to the side between the turbines is $1 \mathrm{D}[6]$.

Shyu performed research on changes in wind speed and the distance between vertical axis wind turbines Savonious to the efficiency of the wind farm. Turbines are used by two axial types. This research was carried out using a wind tunnel of $21 \mathrm{~m} \times 6 \mathrm{~m} \times 2.6-3 \mathrm{~m}(\mathrm{LxWxH})$. Variations made are a distance of $3 \mathrm{~m}, 2.4 \mathrm{~m}$, and $1.8 \mathrm{~m}$ with in-line configuration. The results of this study are the performance of wind turbines increased by $11 \%$ compilation of two VAWT turbines rotated counterclockwise at a distance of 1.5 to 2 times the diameter of the turbine [7].

Sumner reviewed the configuration of two turbines of the same diameter as the tandem, sideby-side, and staggered configurations as shown in Figure 1. The results of this review are the distance the turbine affects fluid behavior. The state of the turbine is classified into 3 depending on the distance applied to each configuration, which is the single bluff body; reattachment regime; coshedding regime [8].

\section{Methodology}

In the following the work by Dragomirescu, turbine performance can be analyzed through the value of the power coefficient $(\mathrm{Cp})$ and torque coefficient $(\mathrm{Ct})[5]$. $\mathrm{Cp}$ and $\mathrm{Cm}$ values can be calculated using the following equation.

$$
\begin{aligned}
& C_{t}=\frac{T}{0.25 \rho v^{2} D_{1} S} \\
& C_{p}=\frac{P}{0.5 \rho v^{3} S}
\end{aligned}
$$

The correlation between power coefficient $(\mathrm{Cp})$ and torque coefficient $(\mathrm{Ct})$ is as follows.

$$
\mathrm{C}_{\mathrm{p}}=\mathrm{C}_{\mathrm{t}} \lambda
$$




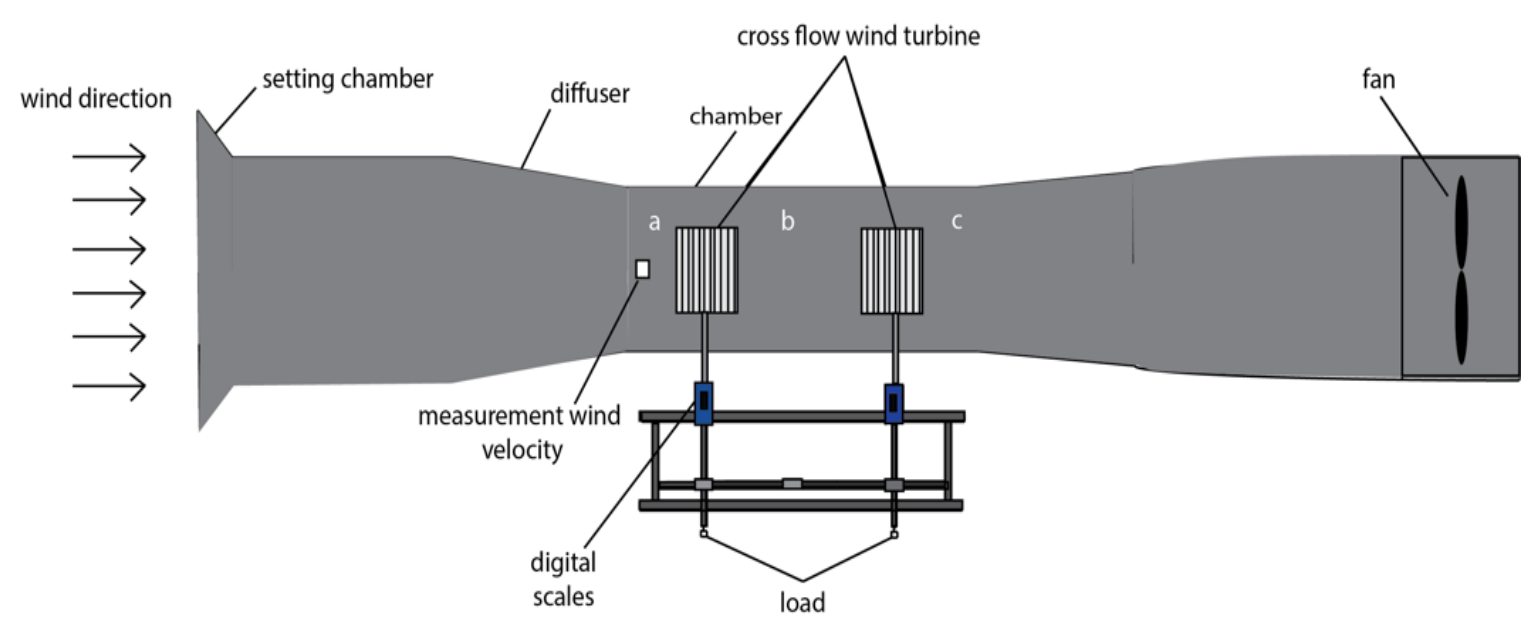

Fig. 1. Sketch of the experimental set up

The efficiency in wind turbine with which a rotor can remove power from the wind relies upon the dynamic coordinating between the rotor and the wind stream. Thus, the performance of a wind rotor is typically described by the varieties in its power coefficient with the tip speed ratio [9]. Tip Speed Ratio is the ratio of rotor speed to free wind speed. For certain wind speeds, the TSR affects the rotational speed of the rotor. tip speed ratio can be calculated by the ratio between the speed of the rotor and wind speed.

$\lambda=\frac{\pi \mathrm{DN}}{60 \mathrm{v}}$

Calculation of shaft torque was using the prony brake method. Measurements on the prony brake are done by wrapping a strap or belt around the engine's output shaft on a spring and one end carrying a load with a certain mass, $m$, and measuring the force transferred to the belt through friction [10] as shown in Figure 2.

$\mathrm{F}_{\mathrm{e}}=\mathrm{mg}-\mathrm{F}_{\mathrm{s}}$

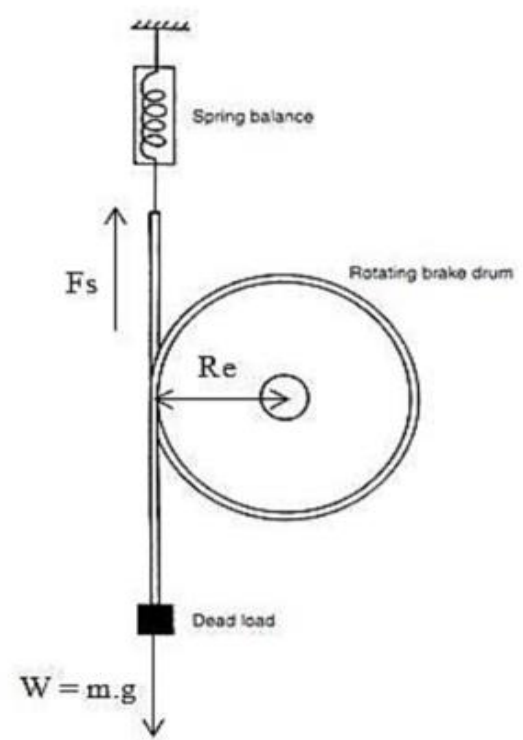

Fig. 2. Prony Brake System [10] 
and torque is obtained from calculations

$\mathrm{T}=\mathrm{F}_{\mathrm{e}} \times \mathrm{R}_{\mathrm{e}}$

The experiment in this study was carried out in the wind tunnel at the Department of Mechanical Engineering at the Sebelas Maret University (UNS). A simple sketch of the experimental setup is presented in Figure 3 . The test section of wind tunnel has a cross sectional area of $30 \mathrm{~cm} \times 30 \mathrm{~cm}$.

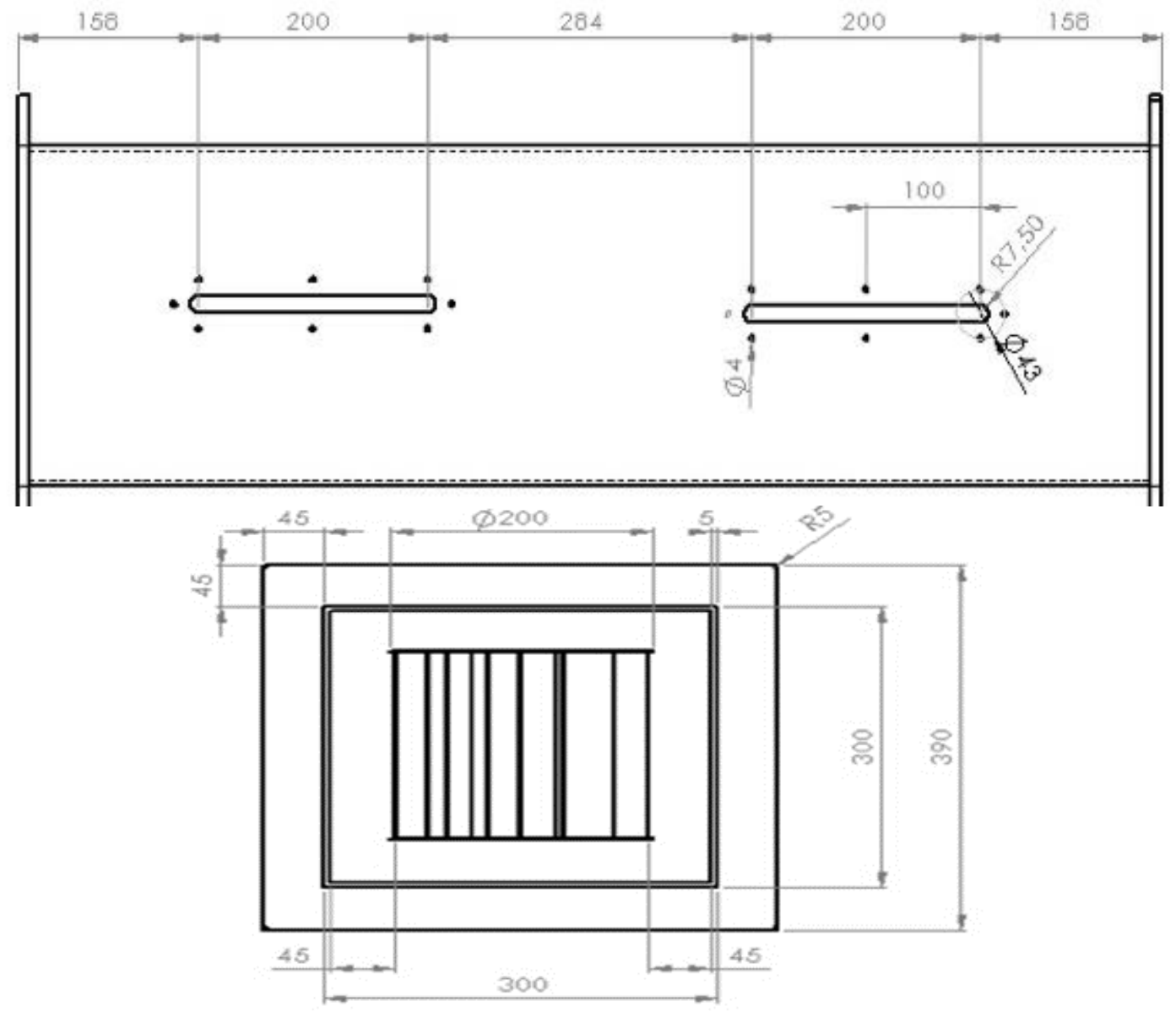

Fig. 3. Sketch of the turbine placement

The turbine, which has a rotor diameter (D) of $20 \mathrm{~cm}$ was installed. The front turbine was installed at a distance $1 \mathrm{D}$ downstream of the inlet of the wind tunnel. The inlet velocity was varied between $5 \mathrm{~m} / \mathrm{s}$ to $7 \mathrm{~m} / \mathrm{s}$ with interval of $1 \mathrm{~m} / \mathrm{s}$ and kept constant during the measurements. The measurement of velocity of the incoming flow was using pitot tube anemometer. All the experiments were conducted at a turbulence inflow with a Re of 5,21 × $10^{5}$. In order to have uniform flow conditions, the roof of the test section was adjusted for a zero-pressure gradient in the streamwise flow direction. Consequently, the mean velocity in the empty tunnel is found to be uniform within \pm $0.6 \%$ [11]. As the wind tunnel is of the type closed-loop, the particles were evenly distributed in the airflow during the returning process.

Figure 4 is showing the variation of distance that was applied during the experiment. The turbine that was used has uniform dimension. The rotation of turbine hat has been used in this experiment is counter-rotating, where the front turbine is rotating clock-wise and the other is rotating counter- 
clock-wise. The use of counter-rotating aims to increase the power coefficient of turbine. Distance that has been applied in this experiment is varied from 1.5D;2D; $2.5 \mathrm{D}$.
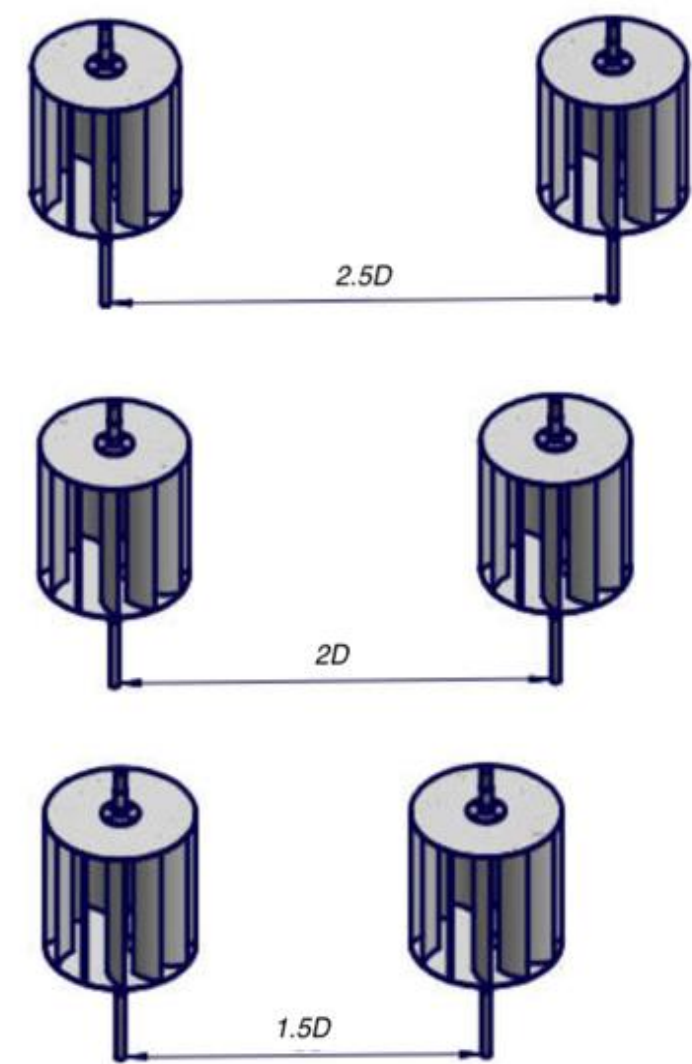

Fig. 4. Percentage of forces on aerodynamic devices

\section{Results}

Research on experiment of this cross-flow wind turbine has the main goal to obtain the greatest possible wind velocity and distance of turbine. The experiment carried out at wind velocity of $5 \mathrm{~m} / \mathrm{s}$, $6 \mathrm{~m} / \mathrm{s}, 7 \mathrm{~m} / \mathrm{s}$. These are the results of the experiment on variation of wind velocity that has been carried out.

Figure 5 shows that the power coefficient value increased with increasing TSR until its maximum point then start to decreased. It also shows that maximum value of power coefficient increased along the wind velocity. On wind velocity of $7 \mathrm{~m} / \mathrm{s}$, it reached the highest power coefficient, which is 0,122 on upstream turbine and 0,082 on downstream turbine. That is because wind velocity affects the turbine's rotation, the greater energy that given on turbine will increase the energy that can be converted into rotation. 


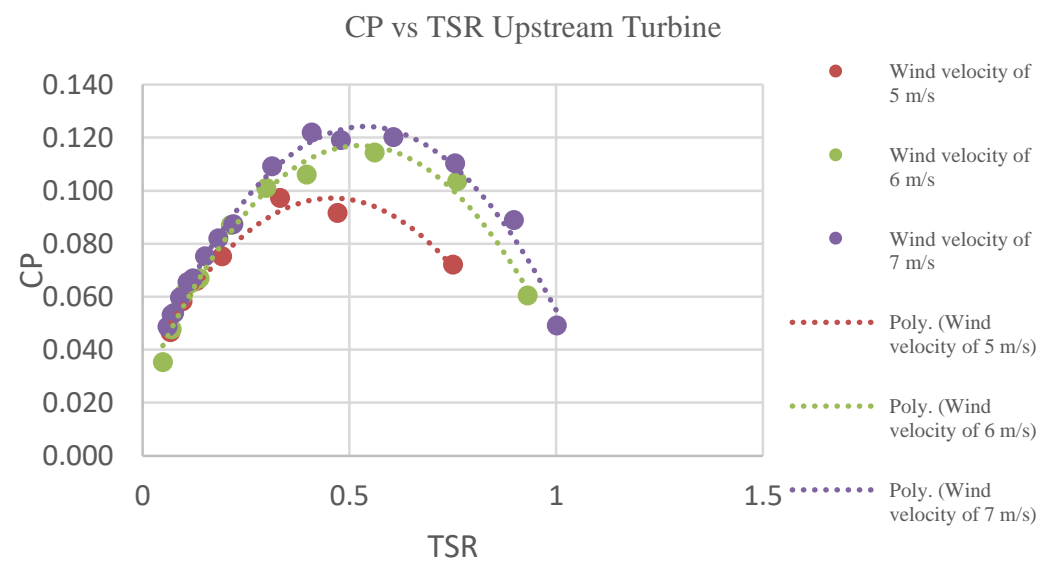

(a)

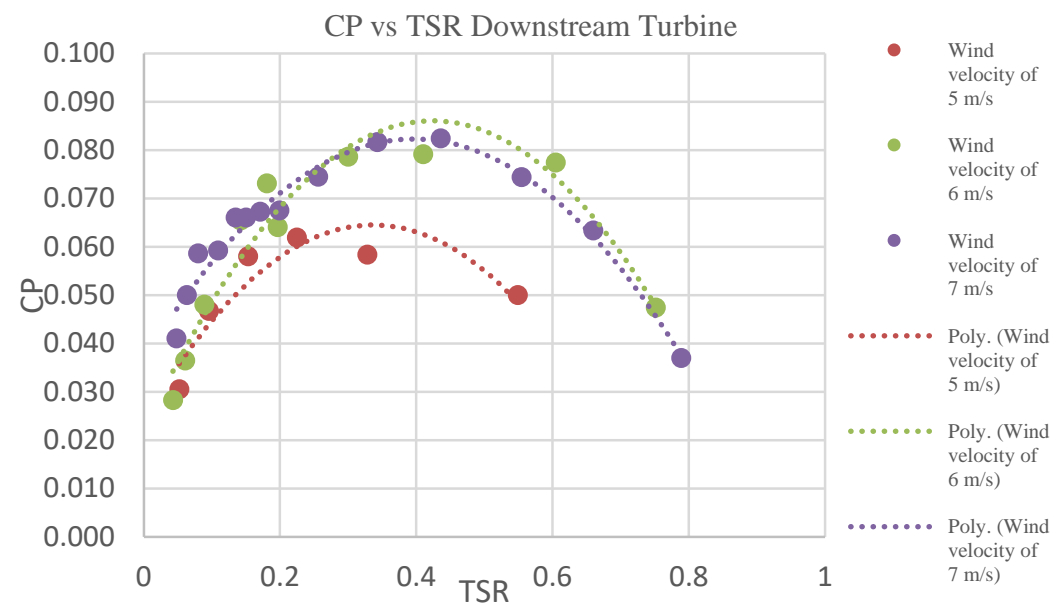

(b)

Fig. 5. Result of Power Coefficient vs TSR on wind velocity variation

Figure 6 shows that the power coefficient value increased with increasing distance of two turbines. On distance of $2.5 \mathrm{D}$, it reached the highest power coefficient, which is 0,122 on upstream turbine and 0,082 on downstream turbine. When two circular cylinders are arranged in-line and parallel to the mean flow in an in-line configuration (Figure 3), the downstream turbine is shielded from the oncoming flow by the turbine immediately upstream. The wake of the upstream cylinder modifies the incoming flow conditions for the downstream turbine, while this second turbine interferes with the wake dynamics and vortex formation region of the upstream turbine. The two cylinders may behave as if a single bluff body or as two independent bodies depending on the spacing between their centres. 


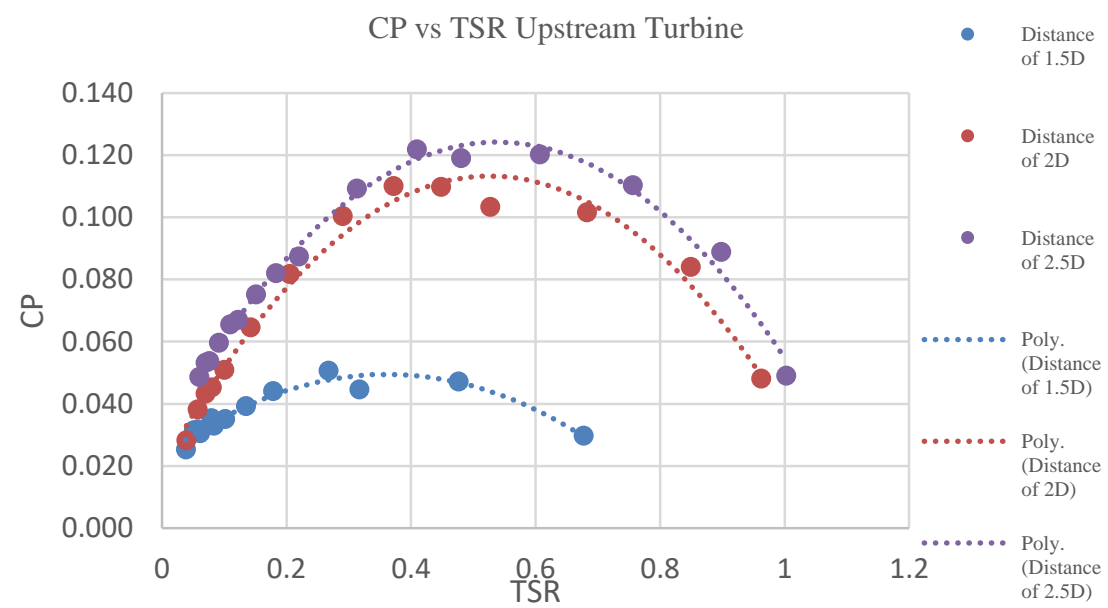

(a)

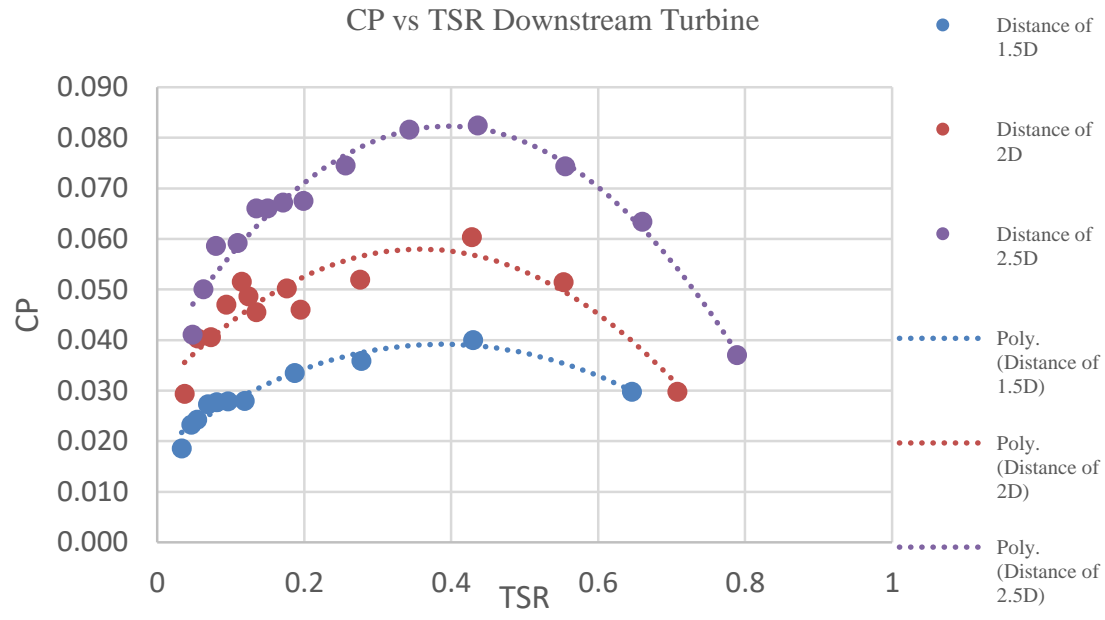

(b)

Fig. 6. Result of Power Coefficient vs TSR on distance variation

At smaller distances, the two turbines are considered as a single "buff body", while at a larger distance the turbines are considered as two separate turbines or "independent bodies". Greater turbine distance forms a vortex in the turbine gap and is trapped, thereby increasing the negative torque inside the turbine. The result of negative torque will affects the torque of the turbine so that the torque decreased [8].

Increasing the distance between turbines reduces the decreased in $\mathrm{Cp}$ value from upstream to downstream turbines. Baloutaki research shows the effect of the streamwise distance of the downstream VAWT turbine position in the downstream rotating on aerodynamic performance. Experimental test results show that at a distance of 1.5D has the lowest $\mathrm{Cp}$ decrease because the turbine is considered as a single "buff body". At 2D distance the turbine is considered as 2 separate turbines or "independent bodies" to form a vortex and a wake effect occurs resulting in a decrease in the value of large $\mathrm{Cp}$. At a distance of 2.5D the decrease in $\mathrm{Cp}$ value decreased compared to 2D distance due to the recovery in the wake effect [6]. 


\section{Conclusions}

Performance of turbine are affected by several factor. Two of the factors that examined in this experiment was wind velocity and distance of turbine in in-line configuration. Both of two factors affected performance of the turibine. On higher wind velocity, power coefficient will increase. It reached 0,122 on upstream turbine and 0,082 on downstream turbine when varied on $7 \mathrm{~m} / \mathrm{s}$ of wind velocity. When varied by distance, the greater distance that applied will also increase the power coefficient of turbine. The higher power coefficient in this experiment is reached when distance was

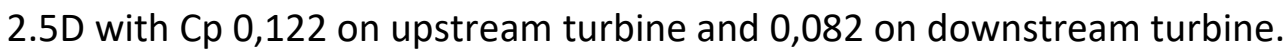

\section{Acknowledgement}

The research is supported by Universitas Sebelas Maret Surakarta through PNBP research grant (PU UNS), T.A. 2018, No: 516/UN27.21/PP/2019.

\section{References}

[1] Jaelani, Aan. "Renewable energy policy in Indonesia: Scientific signs of the Qur'an and its implementation in Islamic economics." (2017).

[2] Harjanto, Nur Tri. "Dampak lingkungan pusat listrik tenaga fosil dan prospek pltn sebagai sumber energi listrik nasional." PIN Pengelolaan Instalasi Nuklir 1, no. 01 (2016).

[3] Kementerian Energi dan Sumber Daya Mineral, Jurnal Energi, 02 ed., Kementerian Energi dan Sumber Daya Mineral, Jakarta, 2016.

[4] Vasel-Be-Hagh, Ahmadreza, and Cristina L. Archer. "Wind farms with counter-rotating wind turbines." Sustainable Energy Technologies and Assessments 24 (2017): 19-30. https://doi.org/10.1016/i.seta.2016.10.004

[5] Dragomirescu, A. "Performance assessment of a small wind turbine with crossflow runner by numerical simulations." Renewable energy 36, no. 3 (2011): 957-965.

https://doi.org/10.1016/i.renene.2010.07.028

[6] Ahmadi-Baloutaki, Mojtaba, Rupp Carriveau, and David SK Ting. "A wind tunnel study on the aerodynamic interaction of vertical axis wind turbines in array configurations." Renewable Energy 96 (2016): 904-913. https://doi.org/10.1016/i.renene.2016.05.060

[7] Shyu, Lih Shyng. "A pilot study of vertical-axis turbine wind farm layout planning." In Advanced Materials Research, vol. 953, pp. 395-399. Trans Tech Publications Ltd, 2014. https://doi.org/10.4028/www.scientific.net/AMR.953-954.395

[8] Sumner, D. "Two circular cylinders in cross-flow: a review." Journal of fluids and structures 26, no. 6 (2010): 849899.

https://doi.org/10.1016/i.jfluidstructs.2010.07.001

[9] Khattak, M. A., NS Mohd Ali, NH Zainal Abidin, N. S. Azhar, and M. H. Omar. "Common Type of Turbines in Power Plant: A Review." Journal of Advanced Research in Applied Sciences and Engineering Technology 3, no.1 (2016): 77100.

[10] Sankaranarayanan, K., S. Krishnakumar, G. Victor PaulRaj, R. Rahul, and S. Chitra Ganapathi. "Wind Tunnel Experiment on a Small Horizontal Axis Wind Turbine." In Eighth Asia-Pacific Conf. Wind Eng., Chennai, India. 2013. https://doi.org/10.3850/978-981-07-8012-8 225

[11] García, Luis, Mari Vatn, Franz Mühle, and Lars Sætran. "Experiments in the wind turbine far wake for the evaluation of an analytical wake model." In Journal of Physics: Conference Series, vol. 854, no. 1, p. 012015. IOP Publishing, 2017.

https://doi.org/10.1088/1742-6596/854/1/012015 